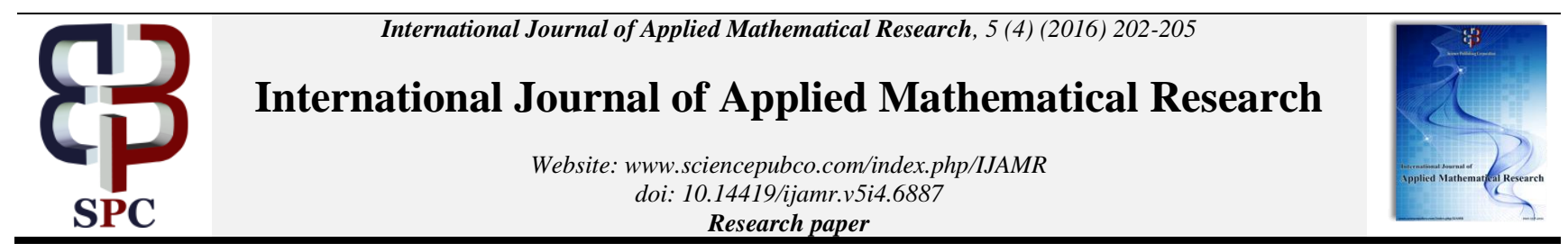

\title{
A numerical method based on explicit finite difference for solving fractional hyperbolic PDE's
}

\author{
Abdulkafi Mohammed Saeed * \\ Department of Mathematics, College of Science, Qassim University, Saudi Arabia \\ *Corresponding author E-mail: abdulkafi.ahmed@qu.edu.sa
}

\begin{abstract}
In this paper, a new numerical scheme based on explicit finite difference approximation for solving fractional hyperbolic partial differential equations (FHPDE's) is formulated. Numerical studies for the model problems are presented to confirm the accuracy and the effectiveness of the proposed method. The obtained results of proposed system are compared with exact solutions and the original system to show the efficient of the new method.
\end{abstract}

Keywords: Fractional Hyperbolic Partial Differential Equations; Preconditioned Explicit Finite Difference Method.

\section{Introduction}

Fractional Partial Differential Equations are extensively used in engineering, physics and mathematical fields, such as porous media, anomalous diffusion, Hamiltonian chaos systems, bioengineering ([1], [2], [3], [4]). They are involved to model physical processes referring to memory properties, genetic characters and path dependence. The fractional hyperbolic partial differential equations (FHPDE's) model the vibrations of structures (e.g. buildings, beams and machines) and are the basis for fundamental equations of atomic physics ([5], [6], [7]). However, only a very few fractional differential equations can be solved analytically because of their complicated form. Hence, the recent rapid development of numerical methods for fractional differential equations has attracted more and more attentions from researchers. The Iterative methods based on the finite difference approximations have been shown suitable for solving the partial differential equations ([8], [9], [10], [11]). Meerschaert and Tadejeran ([12], [13]) proposed a finite difference approximation of fractional advectiondiffusion flow equation and two-sided space-fractional differential equation. In this work, the new preconditioned explicit finite difference approximation will be formulated and applied for solving FHPDE's. The structure of this paper is as follows: Section 2 describes the formulation of the preconditioned explicit finite difference method iterative method for solving the fractional hyperbolic partial differential equations. In section 3 , the stability analysis of the proposed method will be discussed. Numerical results are presented in order to show the efficiency of the proposed method in section 4. Finally, relevant conclusions are drawn in section 5.

\section{Formulation of the preconditioned explicit finite difference method for solving the fhpde's}

Consider the fractional order partial differential equations

$$
\frac{\partial^{2} \mathrm{u}(\mathrm{x}, \mathrm{t})}{\partial \mathrm{t}^{2}}=\mathrm{c}(\mathrm{x}, \mathrm{t}) \frac{\partial^{\alpha} \mathrm{u}(\mathrm{x}, \mathrm{t})}{\partial \mathrm{x}^{\alpha}}+\mathrm{s}(\mathrm{x}, \mathrm{t}), \mathrm{L} \leq \mathrm{x} \leq \mathrm{R}, 0 \leq \mathrm{t} \leq \mathrm{T}
$$

Together with the initial and zero Dirichlet boundary conditions:

$\left.\begin{array}{l}\mathrm{u}(\mathrm{x}, 0)=\mathrm{f}(\mathrm{x}), \mathrm{u}_{\mathrm{t}}(\mathrm{x}, 0)=\mathrm{h}(\mathrm{x}), \mathrm{L} \leq \mathrm{x} \leq \mathrm{R} \\ \mathrm{u}(\mathrm{L}, \mathrm{t})=0, \mathrm{u}(\mathrm{R}, \mathrm{t})=0,0 \leq \mathrm{t} \leq \mathrm{T}\end{array}\right\}$

Where $\frac{\partial^{\alpha} \mathrm{u}(\mathrm{x}, \mathrm{t})}{\partial \mathrm{x}^{\alpha}}$ denote the left-hand partial fractional derivative of order $\alpha$ of the function $\mathrm{u}$ with respect to $\mathrm{x}$ and $1 \leq \alpha \leq 2$.

Nishimoto [14] estimated the left-handed shifted and the righthanded shifted to the left-handed and right-handed derivatives as the following:

$$
\begin{aligned}
& \frac{d^{\alpha} f(x)}{d_{+} x^{\alpha}}=\frac{1}{(\Delta x)^{\alpha}} \sum_{k=0}^{n} g f(x-(k-1) \Delta x), \\
& \frac{d^{\alpha} f(x)}{d_{-} x^{\alpha}}=\frac{1}{(\Delta x)^{\alpha}} \sum_{k=0}^{n} g f(x+(k-1) \Delta x)
\end{aligned}
$$

Where $\mathrm{n}$ is the number of subdivision of interval $[\mathrm{L}, \mathrm{R}]$ and $\alpha$ is the fractional number. Therefore, we can write:

$$
\begin{aligned}
& \frac{\partial^{\alpha} \mathrm{u}\left(\mathrm{x}_{\mathrm{i}}, \mathrm{t}_{\mathrm{j}}\right)}{\partial_{+} \mathrm{x}^{\alpha}}=\frac{1}{(\Delta \mathrm{x})^{\alpha}} \sum_{\mathrm{k}=0}^{\mathrm{i}+1} \mathrm{~g}_{\mathrm{k}} \mathrm{u}\left(\mathrm{x}_{\mathrm{i}}-(\mathrm{k}-1) \Delta \mathrm{x}, \mathrm{t}_{\mathrm{j}}\right) \\
& =\frac{1}{(\Delta \mathrm{x})^{\alpha}} \sum_{\mathrm{k}=0}^{i+1} \mathrm{~g}_{\mathrm{k}} \mathrm{u}_{\mathrm{i}-\mathrm{k}+1, \mathrm{j}}
\end{aligned}
$$

and 


$$
\begin{aligned}
& \frac{\partial^{\alpha} \mathrm{u}\left(\mathrm{x}_{\mathrm{i}}, \mathrm{t}_{\mathrm{j}}\right)}{\partial_{-} \mathrm{x}^{\alpha}}=\frac{1}{(\Delta \mathrm{x})^{\alpha}} \sum_{\mathrm{k}=0}^{\mathrm{n}-\mathrm{i}+1} \mathrm{~g}_{\mathrm{k}} \mathrm{u}\left(\mathrm{x}_{\mathrm{i}}+(\mathrm{k}-1) \Delta \mathrm{x}, \mathrm{t}_{\mathrm{j}}\right) \\
& =\frac{1}{(\Delta \mathrm{x})^{\alpha}} \sum_{\mathrm{k}=0}^{\mathrm{n}-\mathrm{i}+1} \mathrm{~g}_{\mathrm{k}} \mathrm{u}_{\mathrm{i}+\mathrm{k}-1, \mathrm{j}}
\end{aligned}
$$

Where $\mathrm{g}_{0}=1$ and $\mathrm{g}_{\mathrm{k}}=(-1)^{\mathrm{k}} \frac{\alpha(\alpha-1) \ldots(\alpha-\mathrm{k}+1)}{\mathrm{k} !}, \mathrm{k}=1,2, \ldots$

To improve the explicit finite difference method for solving the initial-boundary value problem (1) - (2), we substitute $t_{=}=t_{j}$ in equation (1) and replace the partial derivative $\frac{\partial^{2} \mathrm{u}}{\partial \mathrm{t}^{2}}$ with its central difference approximation to get:

$$
\frac{u_{i, j+1}-2 u_{i, j}+u_{i, j}-1}{(\Delta t)^{2}}=c_{i, j} \frac{\partial^{\alpha} u_{i, j}}{\partial x^{\alpha}}+s_{i, j}
$$

Where $t_{j}=j \Delta t, j=0,1, \ldots, m$ and $m$ is the number of subdivision of the interval $[0, T], t \in R$. Next, substitute equation (3) in equation (5) to obtain:

$$
\begin{aligned}
& \frac{u_{i, j+1}-2 u_{i, j}+u_{i, j}-1}{(\Delta t)^{2}}=\frac{c_{i, j}}{(\Delta x)^{\alpha}} \sum_{k=0}^{i+1} g_{k} u_{i-k+1, j}+s_{i, j} \\
& i=1,2, \ldots, n ; j=0,1, \ldots, m-1
\end{aligned}
$$

Also, the initial and boundary conditions given by equation (2) become:

$$
\left.\begin{array}{l}
u_{r, 0}=u\left(x_{i}, 0\right)=f\left(x_{i}\right), \frac{\partial u\left(x_{i}, 0\right)}{\partial t}=h\left(x_{i}\right) \text { for } i=0,1, \ldots, n \\
u_{0, j}=u\left(L, t_{j}\right)=0, \quad u_{n, j}=u(R, t)=0, \text { for } j=0,1, \ldots, m
\end{array}\right\}
$$

Now, using the central difference approximation to the initial derivative conditions, we can get:

$$
\frac{1}{2 \Delta t}\left(u_{i, 1}-u_{i,-1}\right)=h\left(x_{i}\right), i=0,1, \ldots, n
$$

Which can be written as:

$$
u_{i, 1}=u_{i,-1}+2 \Delta t h\left(x_{i}\right), i=0,1, \ldots, n
$$

Furthermore, equation (6) becomes:

$$
\begin{aligned}
& u_{i, j+1}=2 u_{i, j}-u_{i, j}-1+\frac{(\Delta t)^{2} c_{i, j}}{(\Delta x)^{\alpha}} \sum_{k=0}^{i+1} g_{k} u_{i-k+1, j} \\
& +s_{i, j}(\Delta t)^{2} ; i=1,2, \ldots, n ; j=0,1, \ldots, m-1
\end{aligned}
$$

Therefore:

$$
u_{i, 1}=2 u_{i, 0}-u_{i,-1}+\frac{(\Delta t)^{2} c_{i, 0}}{(\Delta x)^{\alpha}} \sum_{k=0}^{i+1} g_{k} u_{i-k+1,0}+s_{i, 0}(\Delta t)^{2}
$$

By substituting $u_{i,-1}=u_{i, 1}-2 \Delta t h\left(x_{i}\right)$ back into equation (8), one can show that $u_{i, 1}$ can be calculated from the following equation:

$$
u_{i, 1}=f_{i}+\frac{(\Delta t)^{2} c_{i, 0}}{2(\Delta x)^{\alpha}} \sum_{k=0}^{i+1} g_{k} f_{i-k+1, j}+\frac{(\Delta t)^{2}}{2} s_{i, j}+\Delta t g_{i} ; i=1,2, \ldots, n-1
$$

By evaluating the above equation for each $i=1,2, \ldots, n-1$, one can get the values of $u_{i, 1}$.

Then by evaluating equation ( 7 ) at $i=1,2, \ldots, n-1$ and $j=2,3, \ldots, m-1$, one can get the numerical solution of equation (1). The resulting equation can be explicitly solved to give:

$u_{i, j+1}-2 u_{i, j}+u_{i, j-1}=r \sum_{w=0}^{i+1} g_{w} u_{i-w}+1, j$

Where $r=\frac{\mathrm{k}^{2}}{\mathrm{~h}^{\alpha}}$.

It's well known that in the explicit finite difference treatment the PDE or the FPDE are replaced by an algebraic system of equations which can be written as the form

$A \bar{u}=\bar{f}$,

Where, A is nonsingular coefficients matrix, $\overline{\mathrm{u}}=\left[\mathrm{u}_{\mathrm{j}, 1}, \mathrm{u}_{\mathrm{j}, 2}, \ldots, \mathrm{u}_{\mathrm{j}, \mathrm{N}-1}\right]^{\mathrm{T}} \quad$ and $\quad \overline{\mathrm{f}}=\left[\mathrm{f}_{\mathrm{j}, 1}, \mathrm{f}_{\mathrm{j}, 2}, \ldots, \mathrm{f}_{\mathrm{j}, \mathrm{N}-1}\right]^{\mathrm{T}}$, $\mathrm{j}=1,2, \ldots, \mathrm{N}-1$.

Now, from the linear system of equations (10) which formed when fractional hyperbolic partial differential equation is solved by the explicit finite difference method, matrix $\mathrm{A}$ can be write as $\mathrm{A}=\mathrm{D}-\mathrm{L}-\mathrm{U}$ where $\mathrm{D}$ is diagonal matrix $\mathrm{A},-\mathrm{L}$ is strictly lower triangular parts of $\mathrm{A}$ and $-\mathrm{U}$ is strictly upper triangular parts of $\mathrm{A}$. A preconditioner $(\mathrm{I}-\mathrm{kL})$, where: $1 \leq \mathrm{k}<2$ is used to modify the original system (10) to

$(\mathrm{I}-\mathrm{kL}) \mathrm{A} \overline{\mathrm{u}}=(\mathrm{I}-\mathrm{kL}) \overline{\mathrm{f}}$

The resulted system of (11) called preconditioned explicit finite difference method.

\section{Stability analysis}

We can discuss the stability of the resulting equation (9) as the following:

Let $\mathrm{g}_{0}=1$ and $\mathrm{g}_{\mathrm{W}}=(-1) \frac{\mathrm{w} \alpha(\alpha-1) \mathrm{k}(\alpha-\mathrm{w}-1)}{\mathrm{w}} ; \mathrm{w}=1,2, \ldots ; 1 \leq \alpha \leq 2$.

Hence, $g \geq 0$, for all values of $i$. Therefore:

$$
\sum_{w=0}^{i+1} g_{w} \leq g_{1}=-(-\alpha)=\alpha
$$

The difference between the analytical and numerical solutions of the difference equation remains bounded as $\mathrm{j}$ increases.

Let the error $E_{i j}=u\left(h_{i}, k_{j}\right)-u_{i, j}$ then the finite difference equation (9) is stable. Now, we have to find the stability condition under which the error $E_{i j}$ is bounded. Smith [15] shows that the error $\mathrm{E}_{\mathrm{ij}}$ can be written as:

$E_{i j}=e^{\sqrt{-1}} \beta i_{\zeta} j$

By substituting equations (12), (13) into (9), we can get:

$$
\varepsilon-2-\varepsilon^{-1}-\mathrm{r} \alpha \mathrm{e}^{\sqrt{-1}} \beta \mathrm{h}(1-\mathrm{w}) \leq 0
$$

Assume that $\lambda=\beta \mathrm{h}(1-\mathrm{w})$ and substitute it into equation (14), it can be easily getting the following equation for $\mathrm{R}$ as: 


$$
\varepsilon^{2}-\left(2-\mathrm{r} \alpha \mathrm{e}^{\sqrt{-1} \lambda}\right) \varepsilon+1=0
$$

Let $\mathrm{k}=2+\mathrm{r} \alpha \mathrm{e}^{\sqrt{-1} \lambda}$ and $\left|\mathrm{e}^{\sqrt{-1} \lambda}\right| \leq 1$. Hence the values of $\varepsilon$ are:

$\varepsilon_{1}=\frac{\mathrm{k}+\sqrt{\mathrm{k}^{2}-4}}{2}, \varepsilon_{2}=\frac{\mathrm{k}-\sqrt{\mathrm{k}^{2}+4}}{2}$

From equation (13), the error will not grow with time if

$\left|\mathrm{e}^{\sqrt{-1} \lambda}\right| \leq 1$ for all real $\beta$

Equation (16) is called the Von-Neumann's condition for stability Therefore, we will use this equation to find the stability condition of the finite difference equation (9).

We can see that for $r, \alpha$ and $\beta$ are real, the stability will be given while $\varepsilon_{2}$ gives instability. For $-1 \leq \mathrm{k} \leq 1$, the only useful inequality is $\mathrm{k} \leq 1$ and then $2+\mathrm{r} \alpha \mathrm{e}^{\sqrt{-1} \lambda} \leq 1$, where $\left|\mathrm{e}^{\sqrt{-1} \lambda}\right| \leq 1$. Therefore, $r \leq \frac{-1}{\alpha}$ where $1 \leq \alpha \leq 2$.

Hence, $|\mathrm{r}| \leq \frac{1}{2}$ which is the stability condition. We can conclude that the stability results in the finite partial differential equation case as generalization for the corresponding result in the classical hyperbolic partial differential equation.

By the same manner, we can observe that the preconditioned system (11) has the same stability condition because it has the same structure of (10).

\section{Numerical results and discussion}

Several numerical experiments have been conducted to show the superiority of the proposed method for solving fractional hyperbolic partial differential equation. To check the effectiveness of the proposed iterative method; we will use the following modal problem which is the fractional order partial differential equation [16]:

$\frac{\partial^{2} \mathrm{u}}{\partial \mathrm{t}^{2}}=\frac{1}{\Gamma(0.5)} \sqrt{\mathrm{x}} \frac{\partial^{1.5} \mathrm{u}}{\partial \mathrm{x}^{1.5}}-4 \mathrm{x}^{2}+2 \mathrm{x}^{3}-(2.546) \mathrm{x}^{2} \mathrm{t}^{2}$

$+(2.546) \times \mathrm{t}^{2}, 0 \leq \mathrm{x} \leq 2,0 \leq \mathrm{t} \leq 1$,

Together with initial and zero Dirichlet boundary conditions:

$\left.\begin{array}{l}\mathrm{u}(\mathrm{x}, 0)=0, \mathrm{u}_{\mathrm{t}}(\mathrm{x}, 0)=0,0 \leq \mathrm{x} \leq 2 \\ \mathrm{u}(0, \mathrm{t})=0, \mathrm{u}(1, \mathrm{t})=0,0 \leq \mathrm{t} \leq 1\end{array}\right\}$

This problem has the exact solution $u(x, t)=x^{2}(x-2) t^{2}$. Firstly, the numerical solutions based on preconditioned explicit finite difference and the original explicit finite difference were compared with the exact solution to show the accuracy of these iterative methods. Figure 1 shows that the accuracy of the mentioned methods is acceptable. Furthermore, we can observe that the preconditioned explicit finite difference have better accuracy than the original one.

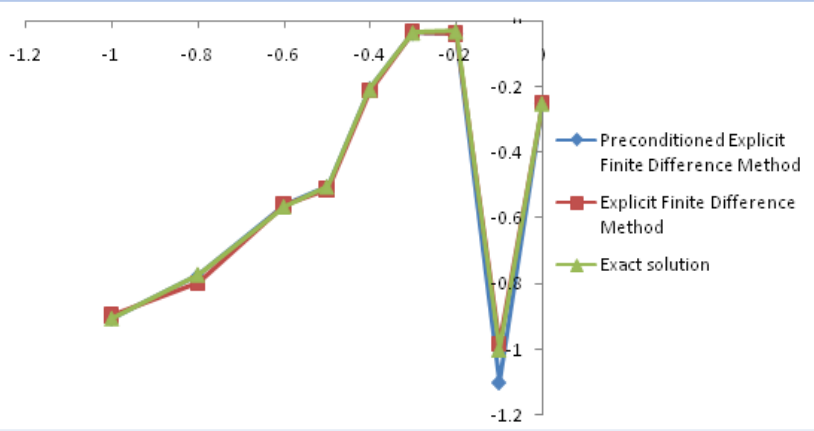

Fig. 1: Comparison of Exact Solution to the Numerical Solution from the Preconditioned and the Original Explicit Finite Difference

In addition to that, Comparisons for Number of iterations and Elapsed time of proposed method and the original one are made for the particular mesh size. Table 1. shows that the proposed method has the lowest number of iterations and elapsed time.

Table 1: Comparison of Number of Iterations and Elapsed Time of Proposed and Original Explicit Finite Difference Methods for Solving the Model Problem

\begin{tabular}{lllllll}
\hline \multicolumn{3}{c}{ N } & \multicolumn{2}{l}{$\begin{array}{l}\text { Explicit Finite Difference } \\
\text { method }\end{array}$} & \multicolumn{3}{c}{$\begin{array}{l}\text { Preconditioned Explicit Finite } \\
\text { Difference }\end{array}$} \\
\cline { 2 - 7 } & $\begin{array}{l}\text { Num- } \\
\text { ber of } \\
\text { itera- } \\
\text { tions }\end{array}$ & $\begin{array}{l}\text { Elapse } \\
\text { d time } \\
\text { (sec.) }\end{array}$ & $\begin{array}{l}\text { Aver- } \\
\text { age } \\
\text { absolute } \\
\text { Error }\end{array}$ & $\begin{array}{l}\text { Number } \\
\text { of itera- } \\
\text { tions }\end{array}$ & $\begin{array}{l}\text { Elapse } \\
\text { d time } \\
\text { (sec.) }\end{array}$ & $\begin{array}{l}\text { Aver- } \\
\text { age } \\
\text { absolute } \\
\text { Error }\end{array}$ \\
\hline 74 & 1572 & 0.0974 & 0.0244 & 1438 & 0.0183 & 0.0192 \\
96 & 1946 & 0.1733 & 0.0194 & 1873 & 0.1532 & 0.0134 \\
162 & 2511 & 0.2521 & 0.0131 & 2360 & 0.2403 & 0.0114 \\
186 & 2815 & 0.2844 & 0.0094 & 2670 & 0.2501 & 0.0063 \\
222 & 3178 & 0.3423 & 0.0064 & 2981 & 0.2904 & 0.0043 \\
246 & 3397 & 0.2874 & 0.0024 & 3165 & 0.1863 & 0.0015 \\
\hline
\end{tabular}

\section{Conclusion}

In this paper, we have formulated new preconditioned explicit finite difference iterative method for solving fractional hyperbolic partial differential equations. From observation of all experimental results, it can be concluded that the proposed scheme may be a good alternative to solve this type of fractional differential equation and many other numerical problems.

\section{Acknowledgement}

Financial support provided by Qassim University for the completion of this research is gratefully acknowledged.

\section{References}

[1] K. Nishimoto, Fractional Calculus: Integrations and Differentiations of Arbitrary Order, Descartes Press Company Koriyama Japan, 1983.

[2] R. Metzler, J. Klafter, The random walk's guide to anomalous diffusion: a fractional dynamics approach. Phys.Rep. 339, 1(2000) 177. https://doi.org/10.1016/S0370-1573(00)00070-3.

[3] G. Zaslavsky, Chaos, fractional kinetics and anomalous transport. Phys. Rep. 371, 6, (2002) 461- 580.

[4] Magin, RL Fractional calculus in bioengineering. Crit. Rev. Biomed. Eng. 32, 1(2004)1- 104.

[5] H. Jafari, V. D. Gejji, Solving linear and nonlinear fractional diffusion and wave equations by adomian decomposition. Appl. Math and Comput., 180(2006) 488-497. https://doi.org/10.1016/i.amc.2005.12.031.

[6] N. H. Sweilam, A. M. Nagy, Numerical solution of fractional wave equation using Crank-Nicolson method. World Appl. Sci. J., 13(2011) 71-75.

[7] N. H. Sweilam, M. M. Khader, A. M. Nagy, Numerical solution of two-sided space fractional wave equation using finite difference method.Journal of Computational and Applied Mathematics, 235, 8(2011) 2832-2841. https://doi.org/10.1016/j.cam.2010.12.002. 
[8] A. R. Abdullah, the Four Point Explicit Decoupled Group (EDG) Method: A Fast Poisson Solver. International Journal of Comp. Math. 38 (1991) 61-70. https://doi.org/10.1080/00207169108803958.

[9] M. Othman, A. R. Abdullah, An Efficient Four Points Modified Explicit Group Poisson Solver, International Journal of Computer Mathematics, 76 (2000) 203-217

[10] A. M. Saeed and N. H. M. Ali, Preconditioned Modified Explicit Decoupled Group Method In The Solution Of Elliptic PDEs, Applied Mathematical Sciences.4 24 (2010) 1165-1181.

[11] A. M. Saeed, N. H. M. Ali, On the Convergence of the Preconditioned Group Rotated Iterative Methods In The Solution of Elliptic PDEs, Applied Mathematics \&Information Sciences, 5, 1, (2011) 65-73.

[12] M. Meerschaert and C. Tadjeran, Finite difference approximations for fractional Advection-dispersion flow equations. J. Comput. Appl. Math. 172, 1, (2004) 65-77.

[13] M. Meerschaert, C. Tadjeran, finite difference approximation for two -sided space fractional partial differential equations, Applied Numerical Mathematics, 56 (2006)80-90. https://doi.org/10.1016/j.apnum.2005.02.008

[14] K. Nishimoto, Fractional Calculus: Integrations and Differentiations of Arbitrary Order, Descartes Press Company Koriyama Japan, 1983.

[15] G. Smith, Numerical Solution of Partial Differential Equations: Finite Difference Methods, Oxford University Press, 1978.

[16] L. Sidiqi, some finite difference method for solving fractional differential equations, M.Sc. Thesis, college of Science, Al-Nahrain University, 2007. 